\title{
Saponin accumulation in the seedling root of Panax notoginseng
}

\author{
Dong Wang, Hongtao Zhu, Keke Chen, Min Xu, Yingjun Zhang*', Chongren Yang
}

\begin{abstract}
Background: Panax notoginseng is an important Chinese medicinal plant. Dammarene-type triterpenoid saponins are main pharmacologically effective compounds in $P$. notoginseng. This study aims to investigate the formation and accumulation of saponins in $P$. notoginseng roots during germination and juvenile stage.

Methods: P. notoginseng seeds were collected and stored in wet sand. After germination, the seedlings were transplanted into a soil nursery bed and cultivated for one year. During this period, samples were collected every month and the concentrations of ginsengnosides $\mathrm{Rg}_{1}, \mathrm{Re}, \mathrm{Rb} \mathrm{b}_{1}, \mathrm{Rd}$ and notoginsengnoside $\mathrm{R}_{1}$ were determined by HPLC.

Results: There was little saponin in the $P$. notoginseng seed. The chemical composition of seed was different from that of root. After germination, $R b_{1}, R_{1}, R e, R d$ and $R_{1}$ appeared successively in the seedling root. And in the fivemonth-old root, all these five main saponins came into existence. The accumulation of saponins in $P$. notoginseng root was affected by seasons.
\end{abstract}

Conclusion: The accumulation of saponins showed a time-dependent increase after germination of $P$. notoginseng.

\section{Background}

Panax notoginseng (Burk.) F. H. Chen. (Sanqi), a species belonging to the Araliaceae family, is an important medicinal plant for its haemostatic and restorative properties [1]. Much chemical and pharmacological research on $P$. notoginseng has been carried out, indicating that dammarene-type triterpenoid saponins are not only the main chemical components but also the main pharmacologically effective components. They exert various effects on the cardiocerebral vascular system, central nervous system and endocrine system [2-7]. To date, over 70 dammarene-type triterpenoid saponins have been isolated from the whole plant of $P$. notoginseng [8-10], with the major saponins isolated from the root being ginsenosides $\operatorname{Rg}_{1}\left(\operatorname{Rg}_{1}\right), \operatorname{Re}(\mathrm{Re}), \mathrm{Rb}_{1}\left(\mathrm{Rb}_{1}\right)$, $\mathrm{Rd}$ ( $\mathrm{Rd}$ ) and notoginsenoside $\mathrm{R}_{1}\left(\mathrm{R}_{1}\right)$.

Although detailed chemical studies have been carried out on mature root and leaf of $P$. notoginseng, very little information is available on the chemical composition of its seed or on saponin accumulation during root

\footnotetext{
* Correspondence: zhangyj@mail.kib.ac.cn

State Key Laboratory of Phytochemistry and Plant Resources of West China, Kunming Institute of Botany, Chinese Academy of Sciences, Kunming 650204, PR China
}

(c) 2011 Wang et al; licensee BioMed Central Ltd. This is an Open Access article distributed under the terms of the Creative Commons Attribution License (http://creativecommons.org/licenses/by/2.0), which permits unrestricted use, distribution, and reproduction in any medium, provided the original work is properly cited.

\section{Methods}

\section{Solvents and chemicals}

Methanol $(\mathrm{MeOH})$ was purchased from Tianjing chemical Ltd (China). Acetonitrile $(\mathrm{MeCN})$ was purchased from Merck (Germany). Standard $\mathrm{Rg}_{1}, \mathrm{Rb}_{1}, \mathrm{Re}, \mathrm{Rd}$ and $\mathrm{R}_{1}$ were isolated from the root of $P$. notoginseng and their chemical structures were determined with nuclear magnetic resonance (NMR) and mass spectrometry (MS).

\section{Plant materials}

Mature seeds were collected from a 3-year-old P. notoginseng in November 2005 from the farm of Miaoxiang Ltd (Wenshan County, Yunnan Province, China). After removal of the pericarp, the seeds were stored in wet sand; after germination, the seedlings were transplanted into a soil nursery bed under a sheltering net with $80 \%$ shadowiness. During this period, 50 g seed or 20 individual seedling roots were sampled at intervals of one month until 
seedlings grew to 12 months old. The samples were dried at $45^{\circ} \mathrm{C}$ and powdered. Concentrations of $\mathrm{Rg}_{1}, \mathrm{Re}, \mathrm{Rb}_{1}, \mathrm{Rd}$ and $R_{1}$ were analyzed with a high-performance liquid chromatography (HPLC).

\section{Seed extraction}

After removal of the pericarp, $100 \mathrm{~g}$ of fresh seeds was crushed and extracted at room temperature with $\mathrm{MeOH}$ $(300 \mathrm{ml})$ for three times. The concentrated $\mathrm{MeOH}$ extract was partitioned between water and petroleum ether. The aqueous part was concentrated under reduced pressure as a crude seed extract $(0.3 \mathrm{~g})$.

\section{HPLC analysis}

A Waters Alliance HPLC (USA) equipped with Alliance separation module 2695 and photodiode array detector 2996 was used in the analysis. A reversed-phase column (Waters Symmetry C-18, $3.9 \times 150 \mathrm{~mm}$ i.d., $5 \mu \mathrm{m}$ ) was used. The gradient elution system consisted of water (A) and acetonitrile (B). Separation was achieved using the following gradient: 0-20 min: $20 \%-22 \% \mathrm{~B}, 20-45$ min: $22 \%-46 \%$ B, $45-55$ min: $46 \%-55 \%$, 55-60 min: $55 \%-$ $90 \% \mathrm{~B}$. The column temperature was set at $25^{\circ} \mathrm{C}$. The flow rate was $1 \mathrm{ml} / \mathrm{min}$. The UV detection wavelength was $203 \mathrm{~nm}$. The mean values of three replicates were calculated.

\section{Method validation}

The method was validated by measuring $R g_{1}, R e, R b_{1}$, $\mathrm{Rd}$ and $\mathrm{R}_{1}$. Instrument precision was obtained by analyzing the peak areas of six injections. The relative standard deviations (RSDs) were: $\mathrm{R}_{1}: 1.09 \%, \mathrm{Rg}_{1}: 0.97 \%$, Re: $1.39 \%, \mathrm{Rb}_{1}: 1.04 \%$ and $\mathrm{Rd}: 1.03 \%$. Stability of sample solution was measured by injecting the same sample solution at time points of $0,6,12$ and 24 hour. The RSDs were: $\mathrm{R}_{1}: 0.96 \%, \mathrm{Rg}_{1}: 0.43 \%$, Re: $1.35 \%, \mathrm{Rb}_{1}: 0.54 \%$ and Rd: $1.41 \%$. Reproducibility was evaluated by measuring the concentrations of these five analytes in six replicate samples with external standards. The RSDs were: $\mathrm{R}_{1}: 0.80 \%, \mathrm{Rg}_{1}: 0.36 \%$, Re: $1.24 \%, \mathrm{Rb}_{1}: 0.58 \%$ and $\mathrm{Rd}$ : $0.50 \%$. The recovery rates of these five saponins were determined by the method of standard addition with six replications. The average recovery rates and the RSDs were calculated (Table 1).

\section{Standard curve}

Standard solutions were prepared by combining $\mathrm{Rg}_{1}$ $(0.332 \mathrm{mg} / \mathrm{ml}), \mathrm{Rb}_{1}(0.344 \mathrm{mg} / \mathrm{ml})$ as standard solutions A whereas $\operatorname{Re}(0.047 \mathrm{mg} / \mathrm{ml}), \mathrm{Rd}(0.082 \mathrm{mg} / \mathrm{ml}), \mathrm{R}_{1}$ $(0.084 \mathrm{mg} / \mathrm{ml})$ as solution $B$; both were dissolved in methanol. The standard curves were generated by injecting standard solutions of $5 \mu \mathrm{l}$ and $10 \mu \mathrm{l}$ to $90 \mu \mathrm{l}$ at the intervals of $10 \mu \mathrm{l}$ respectively. The peak area for each
Table 1 Recovery rates of five main saponins in P. notogingseng

\begin{tabular}{lllll}
\hline Saponin & $\begin{array}{l}\text { Spiked } \\
(\mathbf{m g})\end{array}$ & $\begin{array}{l}\text { Saponin detected } \\
\text { mean }(\mathrm{SD})(\mathbf{m g})\end{array}$ & $\begin{array}{l}\text { Recovery rate } \\
(\mathbf{\%})\end{array}$ & $\begin{array}{l}\text { RSD } \\
(\%)\end{array}$ \\
\hline $\mathrm{R}_{1}$ & 2.68 & $2.74(0.07)$ & 102.2 & 2.44 \\
$\mathrm{Rg}_{1}$ & 18.91 & $20.12(0.15)$ & 106.4 & 0.85 \\
$\mathrm{Re}$ & 0.86 & $0.86(0.02)$ & 100.0 & 2.38 \\
$\mathrm{Rb}$ & 10.60 & $11.27(0.02)$ & 106.3 & 1.81 \\
$\mathrm{Rd}$ & 2.12 & $2.08(0.04)$ & 98.1 & 1.49 \\
\hline
\end{tabular}

Recovery rate $(\%)=($ mean of amount detected/spiked amount $) \times 100 \%$. RSD: relative standard deviation.

analyte was determined. Standard curves were then constructed (Table 2).

\section{Limits of detection and limits of quantitation}

The standard solutions were diluted with $70 \%$ aqueous methanol to provide appropriate concentrations. When the ratio of the testing peak signal-to-noise $(\mathrm{S} / \mathrm{N})$ was 4 , the limit of detection (LOD) for each analyte was determined; when the $\mathrm{S} / \mathrm{N}$ ratio was 10 , the limit of quantitation (LOQ) was determined.

\section{Sample preparation for HPLC analysis}

For seed samples of germination test, $1.0 \mathrm{~g}$ of powder was weighed accurately and extracted ultrasonically for 30 minutes in $70 \%$ methanol in a $10 \mathrm{ml}$ volumetric flask. After cooled down and made up the lost volume with methanol, the sample solution was obtained by filtering the supernate with a nylon filter membrane $(0.45$ $\mu \mathrm{m})$ prior to the HPLC analysis. For seedling root samples, $50 \mathrm{mg}$ of powder was weighed accurately and extracted in $70 \%$ methanol ultrasonically in a $5 \mathrm{ml}$ volumetric flask. The other steps were similar to those of

Table 2 Regression equations of five main saponins in P. notoginseng

\begin{tabular}{|c|c|c|c|c|c|c|}
\hline Saponin & $\begin{array}{l}\text { Regression } \\
\text { equation }\end{array}$ & $P$ & $r^{2}$ & $\begin{array}{l}\text { Test range } \\
(\mu \mathrm{g})\end{array}$ & $\begin{array}{l}\text { LOD } \\
\text { (ng) }\end{array}$ & $\begin{array}{l}\text { LOQ } \\
\text { (ng) }\end{array}$ \\
\hline $\mathrm{R}_{1}$ & $\begin{array}{l}y=584809 x- \\
47740\end{array}$ & $<0.001$ & 0.9999 & $0.42-7.56$ & 1.05 & 2.80 \\
\hline $\mathrm{Rg}_{1}$ & $\begin{array}{l}y=645054 x \\
+46049\end{array}$ & $<0.001$ & 0.9999 & $1.66-29.88$ & 1.11 & 2.77 \\
\hline $\operatorname{Re}$ & $\begin{array}{l}y=616766 x- \\
36027\end{array}$ & $<0.001$ & 0.9993 & $0.24-4.23$ & 1.18 & 2.65 \\
\hline $\mathrm{Rb}_{1}$ & $\begin{array}{l}y=456796 x \\
+125610\end{array}$ & $<0.001$ & 0.9996 & $1.72-30.96$ & 1.15 & 2.46 \\
\hline $\mathrm{Rd}$ & $\begin{array}{l}y=614439 x- \\
14119\end{array}$ & $<0.001$ & 0.9999 & $0.41-7.38$ & 1.02 & 2.73 \\
\hline
\end{tabular}

$y$ : peak area;

$x$ : amount of analyte $(\mu \mathrm{g})$;

LOD: $\mathrm{S} / \mathrm{N}=4$

LOQ: $\mathrm{S} / \mathrm{N}=10$.

$r^{2}$ : coefficient of determination.

$\mathrm{S} / \mathrm{N}$ : signal to noise ratio. 
the seed sample. Injection volumes of seed and seedling sample solutions for HPLC were $100 \mu \mathrm{l}$. As to HPLC analysis of seed extract, the raw extract was dissolved in $\mathrm{MeOH}(10 \mathrm{mg} / \mathrm{ml})$ and filtered with $0.45 \mu \mathrm{m}$ nylon filter membrane and $10 \mu \mathrm{l}$ of solution was injected for HPLC analysis.

\section{Statistical analysis}

Linear regression was performed with Excel 2003 (Microsoft, USA). RSDs were also calculated with Excel 2003 (Microsoft, USA).

\section{Results}

Under the HPLC conditions used in this study, all five saponins were baseline separated and their calibration curves exhibited good linear regressions. The method validation analysis demonstrated that the analytical method developed in this study for all five saponins was accurate and precise.

The $P$. notoginseng seeds were collected in November in our experiments; peeled seeds were stored in wet sand which started to germinate in the following January. Seedlings were then transplanted into a soil nursery bed in February and they would grow till the third February. Samples were collected every month, the contents of ginsenosides $\operatorname{Rg}_{1}, \mathrm{Re}, \mathrm{Rb}_{1}, \mathrm{Rd}$, notoginsenoside $\mathrm{R}_{1}$ were analysed with HPLC. The RSDs of the concentrations of five analytes of each sample in triplicate analyses were all within 3\% (Table 3).

Table 3 Saponin concentrations (\%) in seed and seedling root of $\boldsymbol{P}$. notoginseng during seed germination and juvenile stage

\begin{tabular}{lllllll}
\hline & Month & $\mathbf{R}_{\mathbf{1}}$ & $\mathbf{R g}_{\mathbf{1}}$ & $\mathbf{R e}$ & $\mathbf{R b}_{\mathbf{1}}$ & $\mathbf{R d}$ \\
\hline Seed & Nov & ND & ND- & ND- & ND- & ND- \\
& Dec & ND & ND- & ND- & ND- & ND- \\
& Jan & ND & ND- & ND- & ND- & ND- \\
Seedling root & Feb & ND & ND- & ND- & 0.002 & ND- \\
& Mar & ND & ND- & ND- & 0.061 & ND- \\
& Apr & ND & ND- & ND- & 0.059 & ND- \\
& May & ND & 0.046 & 0.028 & 0.092 & 0.002 \\
& Jun & 0.036 & 0.122 & 0.029 & 0.098 & 0.017 \\
& Jul & 0.056 & 0.232 & 0.036 & 0.106 & 0.018 \\
& Aug & 0.062 & 0.322 & 0.049 & 0.240 & 0.050 \\
& Sep & 0.168 & 0.664 & 0.077 & 0.405 & 0.107 \\
& Oct & 0.214 & 0.552 & 0.095 & 0.627 & 0.122 \\
& Nov & 0.178 & 0.566 & 0.111 & 0.439 & 0.074 \\
& Dec & 0.158 & 0.541 & 0.092 & 0.431 & 0.078 \\
& Jan & 0.146 & 0.375 & 0.063 & 0.380 & 0.053 \\
& Feb & 0.109 & 0.447 & 0.051 & 0.309 & 0.040 \\
\hline
\end{tabular}

ND: not detected.

\section{Saponins in the seed}

Results of HPLC analyses indicated that saponins were undetectable in $P$. notoginseng seed, even though the amount of seed sample was 10 times as much as that of seedling root. We obtained just $0.3 \mathrm{~g} \mathrm{MeOH}$ extract from $100 \mathrm{~g}$ of fresh seed with the yield being $0.3 \%$; yield was about $0.83 \%$ in dried seed while it may reach $9.25 \%$ and $11.74 \%$ of total saponin in dried two-year-old and three-year-old roots respectively [11]. Furthermore, HPLC analysis indicated that $\mathrm{Rg}_{1}, \mathrm{Rb}_{1}, \mathrm{Rd}, \mathrm{Re}$ and $\mathrm{R}_{1}$ (the main constituents in the root) were not detected in the crude seed extract whereas some other peaks appeared in the HPLC chromatogram, suggesting that the chemical composition of the seed was different from that of root (Figure 1). Further comprehensive chemical studies are required to determine the constituents of seed extract.

\section{Saponin accumulation in the root}

After germination, $\mathrm{Rb}_{1}$ first appeared in the seedling root in February. $\mathrm{Rg}_{1}$, $\mathrm{Re}$, and $\mathrm{Rd}$ began to appear in the fourth month of germination (the following May). After one month, all these five saponins were detected in the root. Then, with the growth of seedling, the saponin contents increased rapidly in the root. The accumulation showed a time-dependent increment of saponin contents. $\operatorname{Rg}_{1}$ concentration reached its maximum in September (eight months after germination). $\mathrm{Rb}_{1}$, $\mathrm{Rd}$ and $R_{1}$ reached maximum in October whereas $R e$ did in November. Later, as winter came, concentrations of all

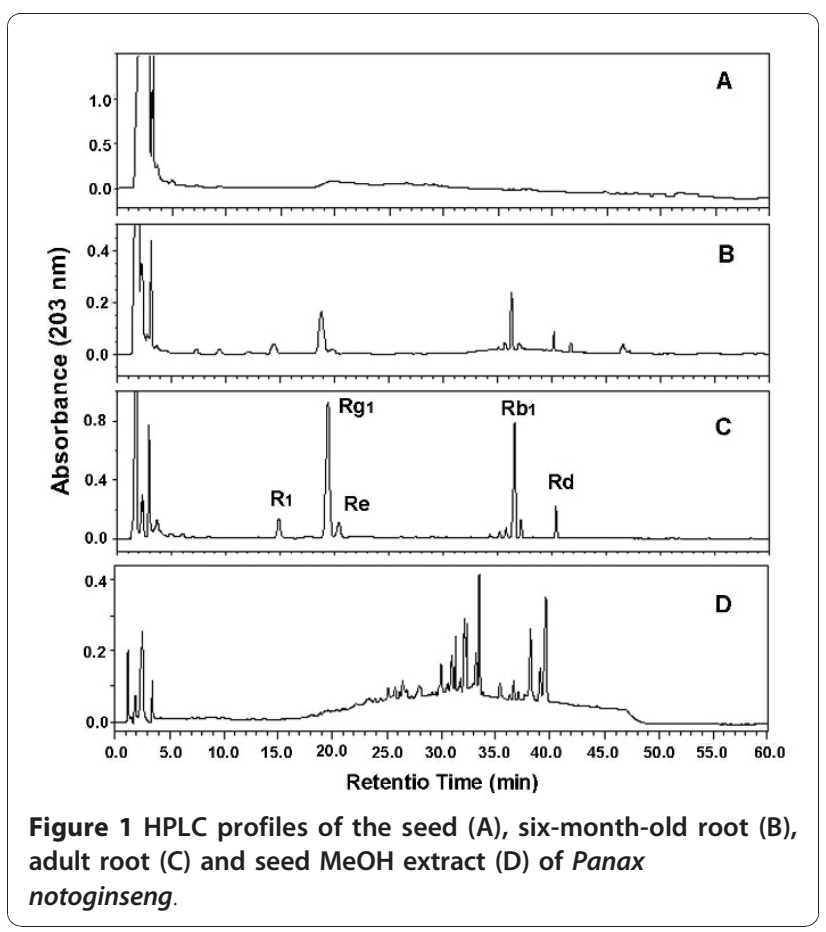


these five saponins started to decline significantly (Figure 2, Table 3).

\section{Discussion}

Dammarene-type triterpenoid saponins are main secondary metabolites of Panax notoginseng. The present study demonstrates a temporal and spatial distribution of saponins during the germination process and the growth of young plants. Our results show that ginsenosides $\operatorname{Rg}_{1}, \mathrm{Re}, \mathrm{Rb}_{1}$, $\mathrm{Rd}$ and notoginsenoside $\mathrm{R}_{1}$ were not detected in $P$. notoginseng seed. The formation of saponins in root is a gradual process. The synthesis and accumulation of saponins began after germination and continued with the growth of seedling. Saponin synthetases were activated after seed began to germinate. In young roots, saponin constituents formed and accumulated mainly between July and October, the most vigorous period of growth. This periodic change is, as in adult plant, closely related to the growth pattern of Panax notoginseng; the formation and accumulation of saponins were affected by seasons [12]. As a plant grows up, more and more saponins accumulate in the root. Our previous work revealed that, in a 3-year-old root, the concentrations of $\mathrm{Rg}_{1}, \mathrm{Rb}_{1}, \mathrm{Rd}, \mathrm{Re}$ and $\mathrm{R}_{1}$ reached $4.11 \%, 4.12 \%, 0.82 \%, 0.83 \%$ and $1.14 \%$ respectively [11]. All these findings suggest that saponins may not serve as the nutrient storage in the seed. The protective functions of saponins in other plants are reported [13,14]. The role of this kind of secondary metabolites in $P$. notoginseng requires further investigation.

\section{Conclusion}

The accumulation of saponins showed a time-dependent increase after germination of $P$. notoginseng.

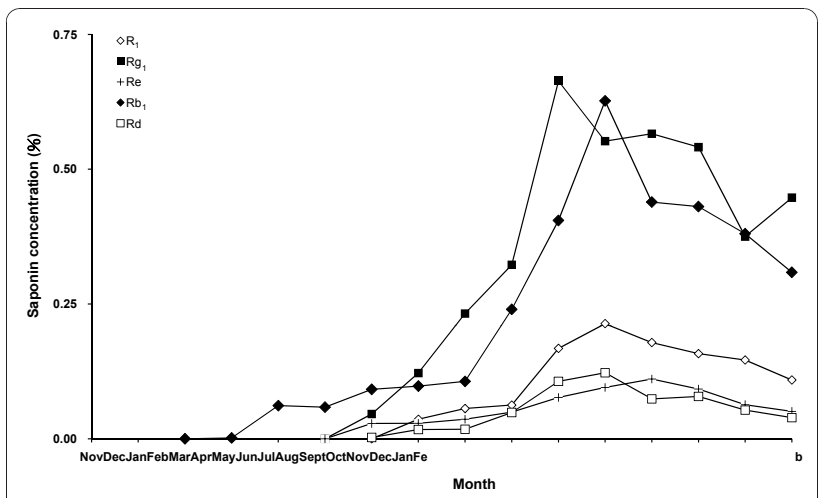

Figure 2 Time courses of saponin accumulation in Panax notoginseng seed and seedling root. The seeds were collected in November and stored in wet sand. They began to germinate the following January. The seedlings were then allowed to grow for one year in soil nursery bed.
Acknowledgements

This work was funded by the Science \& Technology Bureau of Yunnan Province, China (Grant: 2008IF006).

\section{Authors' contributions}

DW, YJZ and CRY designed the study. DW, HTZ and KKC carried out the cultivation. DW and MX performed the chemical analyses. DW, YJZ and CRY wrote the manuscript. HTZ and KKC cultivated and collected the samples. CRY coordinated the study. All authors read and approved the final version of the manuscript.

\section{Competing interests}

The authors declare that they have no competing interests.

Received: 4 September 2010 Accepted: 24 January 2011

Published: 24 January 2011

\section{References}

1. Zheng GZ, Yang CR: Biology of Panax notoginseng and Its Application Beijing: Science Press; 1994

2. Li SH, Chu Y: Anti-inflammatory effects of total saponins of Panax notoginseng. Acta Pharmacol Sin 1999, 20:551-554.

3. Jiang KY, Qian ZN: Effects of Panax notoginseng saponins on post hypoxic cell damage of neurons in vitro. Acta Pharmacol Sin 1995, 16:399-402.

4. Matsuura H, Kasai R, Tanaka O, Saruwatari Y, Fuwa T, Zhou J: Further studies on dammarane-saponins of Sanchi-Ginseng. Chem Pharm Bull (Tokyo) 1983, 31:2281-2287.

5. Sengupta S, Toh SA, Sellers LA, Skepper JN, Koolwijk P, Leung HW, Yeung HW, Wong RNS, Sasisekharan R, Fan TPD: Modulating angiogenesis: the yin and the yang in ginseng. Circulation 2004, 110:1219-1225.

6. White CM, Fan C, Chow M: An evaluation of the hemostatic effect of externally applied notoginseng and notoginseng total saponins. J Clin Pharmacol 2000, 40:1150-1153.

7. Yuan JQ, Guo WZ, Yang BJ: 116 cases of coronary angina pectoris treated with powder composed of radix ginseng, radix notoginseng and succinum. J Tradit Chin Med 1997, 17:14-17.

8. Wang CZ, McEntee E, Wicks S, Wu JA, Yuan CS: Phytochemical and analytical studies of Panax notoginseng (Burk.) F.H. Chen. J Nat Med 2006, 60:97-106.

9. Wang XY, Wang D, Ma XX, Zang YJ, Yang CR: Two new dammarane-type bisdesmosides from the fruit pedicels of Panax notoginseng. Helv Chim Acta 2008, 91:60-66.

10. Komakine N, Okasaka M, Takaishi Y, Kazuyoshi K, Murakami K, Yoshihide Y: New dammarane-type saponin from roots of Panax notoginseng. I Nat Med 2006, 60:135-137.

11. Wang D, Li HZ, Chen KK, Yang CR: HPLC Comparative analysis of ginsenoside Saponins in different underground parts of Panax notoginseng. Acta Botanica Yunnanica 2005, 27:685-690.

12. Tian TXD, Xiu MC, Zong HS, Kui JZ, Zhao NJ, Chun KL, Karl WKT: Chemical assessment of roots of Panax notoginseng in China: Regional and seasonal variations in its active constituents. J Agric Food Chem 2003, 51:4617-4623.

13. Morrissey JP, Osbourn AE: Fungal resistance to plant antibiotics as a mechanism of pathogenesis. Microbiol Mol Biol Rev 1999, 63:708-724.

14. Hammerschmidt R: Secondary metabolites and resistance: more evidence for a classical defense. Physio Mol Plant Patho 2004, 65:169-170.

doi:10.1186/1749-8546-6-5

Cite this article as: Wang et al: Saponin accumulation in the seedling root of Panax notoginseng. Chinese Medicine 2011 6:5. 